\title{
Affect and Strategy Use: The Relationship between EFL Learners' Self-esteem and Language Learning Strategies
}

\author{
Amir Asadifard \\ Department of Foreign Languages, Khorasgan (Isfahan) Branch, Islamic Azad University, Isfahan, Iran \\ Reza Biria \\ Department of Foreign Languages, Khorasgan (Isfahan) Branch, Islamic Azad University, Isfahan, Iran
}

\begin{abstract}
The purpose of this study was to investigate the relationship between Language Learning Strategies (LLSs) and Global Self-esteem (GSE) among college-level EFL learners. It was also meant to know which strategies are more frequent among learners. One hundred and twenty seven undergraduate students majoring in English at Lorestan University participated in the study. Two questionnaires, i.e. the Oxford's (1990) Strategy Inventory for Language Learning (SILL), and the Rosenberg Self-Esteem Scale (RSES), were used for data collection. The data obtained were subjected to descriptive statistics, and correlational analyses were done to determine the relationship between total GSE and total LLSs as well as the six categories of learning strategies, separately. Also, t-tests were conducted to compare self-esteem mean scores of high and low strategy users. Males and females' LLSs and GSE were then compared using t-test. The findings of the study revealed that LLSs correlate significantly with GSE. Among LLS categories, cognitive strategies and compensation strategies indicated the highest correlation with the learners' self-esteem. However, affective strategies were the least correlated category with self-esteem. Furthermore, it was indicated that gender is not a determinant factor for being a high or low strategy user, and does not affect self-esteem.
\end{abstract}

Index Terms - language learning strategies (LLSs), global self-esteem (GSE), strategy categories

\section{INTRODUCTION}

The crucial role that affect has in language learning was neglected for long perhaps due to overemphasizing on cognitivity. However, there has been a growing interest in variables related to affective factors (e.g. Shumann, 1997, 1988) and their relationship with other variables in language teaching, with the hope that research findings will help researchers and practitioners who have been always in search of suitable methods to make teaching profession as effective as possible.

Self-esteem is one of the affective factors which seems to be related to strategy use. Nonetheless, insufficient research in this area does not allow a sound judgment about this relationship. Some scholars such as Robin and Stern (1975) believe that frequent strategy use is one of the characteristics of good language learners. Furthermore, it is believed that discovering the relationship between self-esteem and language learning strategies will help understand how students' judgments toward themselves may affect their strategy application and the kind of strategies they use for learning. In so doing, they can also help learners know their potentials better, and be aware of their perceived values of themselves as well. Since one of the aims of teaching is to teach learners how to learn, students' knowledge of their level of self-esteem, which is their judgment of their worth, may help them choose strategies which best fit their personalities. Therefore, discovering the relationship between the two variables, i.e., language learning strategies and self-esteem is of focus in this study.

Richards and Schmidt (2002, p. 475) define self-esteem as, "a person's judgment of their own worth or value, based on a feeling of 'efficacy', a sense of interacting effectively with one's own environment". Brown (2000) states with caution that self-esteem is the most widespread aspect of human behavior. He further claims that successful cognitive or affective activities cannot be carried out without 'some degree of self-esteem, self-confidence, knowledge of yourself and belief in your own capabilities for that activity' (p.145). There are also some classifications for self-esteem presented by researchers. We adhere to that of Brown's (2000) based on which self-esteem encompasses three levels: The first is general or global self-esteem. This type of self-esteem seems to be relatively consistent and is not easily changed except for some prolong treatments. It can be interpreted as that kind of self-esteem by which one makes of one's own worth through time and in different situations. It has also been compared to mean score or median point of the total self-appraisal. The second is situational or specific self-esteem. As the name implies, it refers to that kind of self-esteem which is associated with a particular situation, for example social interactions, workplace, or some other specific traits such as communicative and athletic ability and intelligence. Other examples can be personality traits such as 'gregariousness, empathy, and flexibility' (p.145). A third type of self-esteem is associated with specific tasks within 
specific situations. This is called 'task self-esteem' such as the self-esteem related to a subject within the broader domain of education. Another example which is related to sports is kicking ability within the broader area of soccer. Task-self-esteem and situational self-esteem have some manifestations in the realm of second language acquisition where learners have different abilities and attitudes toward different tasks. Language skills, as Brown (2000) states, and also specific exercises done in class are clear examples.

There have been many studies carried out on the relationship between people's views of themselves including selfesteem and their success in different aspects of learning. Byrne (2000), for instance, investigated the relationship between anxiety, fear, self-esteem, and coping strategies in post-primary students. Despite measurement difficulties, a large body of research has demonstrated consistently the existence of a positive correlation between high self-esteem and academic achievement (see Burns 1982 for a review of some of this literature). There is little doubt that for most people, positive achievement leads to high self-esteem, but the effect of high self-esteem on achievement is more equivocal. What does seem highly likely, however, is that the self-concept may well perform an important inner mediating function in the learning process (Gurney 1986).

Moreover, a variety of definitions has been presented to describe learning strategies (e.g. Cohen, 1998; O’Malley\& Chamot, 1990). We adhere to Oxford's (1990) in which language learning strategies are the operations employed by the learner to acquire, store, retrieve and use information more efficiently. Thus, a language learning strategy is considered as a conscious technique used by a learner to purposely assist the language learning process.

Research on language learning strategies started with the studies of good language learners in the mid-1970s. Brown (2000) believes that the differences among learners in mastering a second language have motivated researchers to investigate the possible causes to this phenomenon. The results of the studies conducted in the last decade is indicative of the influence some factors such as cognitive, affective, and sociocultural factors have on second language acquisition.

Researchers were interested in determining what distinguished "good" from "poor" language learners and thereby characterizing the features of successful language learners (e.g. Robin, 1975). Since then, a large body of research has focused on identifying the strategies employed by language learners to facilitate their learning.

There have been various points of view as to how we should classify strategies . The most recent and comprehensive inventory is that of Oxford's (1990), i.e., Strategy Inventory for Language Learning (SILL). It consists of 50 strategies classified into six major categories, including memory, cognitive, compensation, metacognitive, affective, and social. Memory strategies, like grouping, associating, or using imagery, "have a highly specific function: helping students store and retrieve new information" (Oxford, 1990, p.71); cognitive strategies, such as highlighting, analyzing, or summarizing messages, "enable learners to understand and produce new language by many different means" (p.37); compensation strategies, like guessing or using synonyms, help learners use the language disregarding their deficiency in language knowledge; metacognitive strategies, like arranging, planning, and evaluating one's learning, allow learners to control their own cognition through planning, arranging, focusing, and evaluating their own learning; affective strategies like deep breathing and using checklists, help learners control their feelings, motivations, and attitudes related to language learning; and social strategies, like asking questions or cooperating with others, facilitate learning to learn with others in a discourse situation (p.37). Also, a body of research has been conducted to indicate which group of strategies are the most and least preferred ones (e.g. Oxford et. al., 1989). The researchers, considering what was mentioned above, aimed at discovering the relationship between total language learning strategies along with strategy categories and global self-esteem. At the same time it was meant to discover the frequency of strategies used by EFL learners in the described context.

\section{METHOD}

\section{A. Participants}

The study was conducted with undergraduate students majoring in English at the state University of Lorestan. The age range was 18 to 28 . The participants were one hundred and twenty seven college students who were studying English literature at the time of the study. The sample contained 32 males $(25.19 \%)$, and 95 females $(74.80 \%)$ and consisted of 36 freshmen (28.34\%), 31 sophomores (24.40\%), 23 juniors $(18.11 \%)$, and 37 seniors (29.13\%). The results can be generalized to total EFL instruction, in this age range, in Iran since the sample has been selected from this whole population.

\section{B. Instruments}

Two questionnaires were used in this study:

1. The Rosenberg Self-Esteem Scale (RSES)

2. Strategy Inventory for Language Learning (SILL)

The Rosenberg Self-Esteem Scale (RSES)

In order to assess global self-esteem, the Rosenberg Self-Esteem Scale (Rosenberg, 1965) was utilized. This scale is widely used for measuring Global Self-esteem (GSE) and consists of 10 items. The RSES uses a 4-point Likert-type scale. Among different types of self-esteem such as global, specific, task, academic, etc., described above, this scale measures global self-esteem which is of focus in this study. In other words, the items of this scale are not concerned with specific characteristics (Rosenberg, Schooler, \& Schoenbach, 1989). 


\section{Strategy Inventory for Language Learning (SILL)}

The Persian version of the 50-item Strategy Inventory for Language Learning (SILL) (Oxford, 1990), was the second instrument utilized in this study. It was translated into Persian by Tahmasebi (1999) and has been used by some researchers (e.g. Rezaei \& Almasian, 2007) to investigate Persian speakers' learning strategies.

Issues of Reliability and Validity

The Rosenberg Self-Esteem Scale (RSES)

The Rosenberg Self-esteem Scale (RSES) is the most widely used scale for measuring GSE (Blascovich \& Tomaka, 1991; cited in Tahriri, 2003). A number of studies have been carried out to investigate the validity and reliability of the RSES. Positive relationship was found between scores on the RSES and scores on some other scales including the Coopersmith Self-Esteem Inventory (Demo, 1985; cited in Tahriri, 2003). In order to determine the reliability of this scale, Cronbach's alpha was utilized. The whole data were subjected to alpha reliability analysis. The RSES achieved an alpha coefficient of .72. This suggests that the items of the RSES are internally consistent based on the data set.

Strategy Inventory for Language Learning (SILL)

In general, the ESL/EFL SILL reliabilities have been very high. A number of studies have revealed high reliabilities for the SILL. To name a few, it was .92 with a sample of 255 Japanese university and college learners (Watanabe, 1990), .93 with 332 Korean university EFL learners (Park, 1994), and in the range of .91 to .95 for the 80-item questionnaire (Oxford and Ehrman, 1995, Oxford and Nykios, 1989). We also calculated the reliability of the 50-item Persian version of SILL utilizing Cronbach's alpha coefficient. It proved to be .91 .

\section{Data Collection}

The two questionnaires were administered by the researchers to the university students at their class time during the second semester of the year 2013. There were seven classes. In each class, students were briefed about the purpose and nature of the study beforehand. Then, they were given instruction as to how to answer the questions. All students agreed to fill in the questionnaires.

The SILL items were in Persian, but RSES questions were in English so the participants were asked to check unknown English words in RSES by using the glossary attached to the RSES or by asking the researcher. The two questionnaires were collected after the participants had finished. The administration of both questionnaires lasted a whole session, i.e., one and a half hours. It should be noted that some of the questionnaires were discarded because they had not been worked on as requested.

\section{Analysis Procedures}

After the data collection through administration of the questionnaires, a data matrix was prepared. As a result, the FEL learners' LLSs score and self-esteem level could be measured. The questionnaires were of Likert-type with five points for the SILL and four points for the RSES. Each of the items in SILL ranged from "Always true of me" to "Never true of me". The score for the item "Always true of me" was 5, "Generally true of me", 4, "somewhat true of me", 3, "Generally not true of me", 2, and "Never true of me" was equated with 1. A similar method was utilized for GSE in which each item ranged from "Strongly agree" to "strongly disagree". In this scale, selecting "Strongly agree" was equal to 4, "Agree" to 3, "Disagree" to 2, and "Strongly disagree" to 1.

As for SILL, the scores of individual items were added up in order to calculate each strategy category score as well as the total score of all categories for each individual. However, according to the instructions attached to the RSES as how to calculate the score, items $1,2,4,6$, and 7 were scored reversely. Then, the sum of the individual items was added to reach each learner's GSE level.

Correlational analysis was done to measure the degree of GSE and total LLSs. Thus it became possible to determine the relationship between the two variables irrespective of the role of sex and instructional level. Also correlation analyses were run for each category and its corresponding GSE. The whole sample was divided into two groups of high and low strategy users, using median-point split procedure. It was meant to know if gender is a determining factor of having high/low self-esteem and being higher/lower strategy users. To this end, the LLSs and GSE scores were divided into two groups, separately, according to the learners' sex. T-tests were run to determine the significance of the difference in the performance of males and females on the SILL and RSES irrespective of their instructional level. The level of 0.05 was used as the criterion of significance.

To analyze the data, the SPSS software (version 20) which is commonly used for analyzing the results of social sciences studies was utilized.

\section{RESULTS}

The data demonstrated that metacognitive strategies was the most preferred subset (Mean=387.44) among the six categories, while affective strategies (Mean=295.83) was the least frequent strategy subset. The second to the fifth categories were compensation (Mean=351.66), cognitive (Mean=349.66), social (Mean=331.64), and memory (302.11) strategies, respectively. Table 1 below summarizes the results. 
TABLE 1

FREQUENCY OF USE FOR STRATEGY CATEGORIES

\begin{tabular}{|l|l|l|l|l|}
\hline Rank & St. category & No. of items & Mean & SD \\
\hline 1st & Metacognitive & 9 & 387.44 & 26.05 \\
\hline 2nd & Compensation & 6 & 351.66 & 35.44 \\
\hline 3rd & Cognitive & 14 & 349.66 & 26.00 \\
\hline 4th & Social & 6 & 331.64 & 40.31 \\
\hline 5th & Memory & 9 & 302.11 & 68.00 \\
\hline 6th & Affective & 6 & 295.83 & 67.22 \\
\hline
\end{tabular}

It was also found that item 33, i.e., "I try to find out how to be a better learner of English", which was one of the metacognitive strategies, was the most preferred strategy used by learners. On the other hand, the least number of learners was proved to choose item 5, namely, "I rhyme to remember new English words". That is to say, this item was the least favored individual strategy by the participants (See appendix A for more information).

To determine the degree of going-togetherness of the learning strategies (LLSs) and global self-esteem (GSE), correlational analyses were done for the whole population's GSE and LLSs. A positive and statistically significant correlation was found between LLSs and GSE ( $r=0.49, \mathrm{p}<0.05, \mathrm{n}=127)$. Also, correlational analyses were done for GSE and the six categories of learning strategies, i.e., memory, cognitive, compensation, metacognitive, affective and social strategies. Metacognitive strategies, among different categories of LLS were the most preferred strategies by the learners and affective strategies were the least used ones. Table 2 below indicates the results of the correlational analyses.

TABLE 2

PEARSON CORRELATION BETWEEN CATEGORIES OF LLSS AND GSE

\begin{tabular}{|c|c|c|c|c|c|c|}
\hline Strategies & $\begin{array}{l}\text { Memory } \\
\text { strategies }\end{array}$ & $\begin{array}{l}\text { Cognitive } \\
\text { strategies }\end{array}$ & $\begin{array}{l}\text { Compensation } \\
\text { strategies }\end{array}$ & $\begin{array}{l}\text { Metacognitive } \\
\text { strategies }\end{array}$ & $\begin{array}{l}\text { Affective } \\
\text { strategies }\end{array}$ & $\begin{array}{l}\text { Social } \\
\text { strategies }\end{array}$ \\
\hline GSE & $\mathrm{r}=0.40$ & $\mathrm{r}=0.47$ & $r=0.46$ & $\mathrm{r}=0.31$ & $\mathrm{r}=0.18$ & $\mathrm{r}=0.36$ \\
\hline
\end{tabular}

Some of the results of the present study are in line with the previous studies with regard to the order of strategy subsets, and there are also some differences. Oxford and Ehrman (1995) demonstrated that compensation strategies were the most preferred strategy category among 855 adults in an intensive training at the US Department of State. In the same study, social, cognitive, and metacognitive strategies were the second, third, and the fourth strategy subsets, respectively. The data obtained through this study showed similar results to the aforementioned research concerning the rank order of cognitive, memory, and affective categories which came third, fifth, and sixth in both studies. According to one study by Oxford and Nykios (1989), affective and memory strategies received the lowest frequencies. This is similar to the results of the present study, while the most frequent strategies were social, metacognitive, cognitive, and compensation strategies.

Using median-point split procedure, the sample was divided into two halves: high and low strategy users. The median score was 131 . Therefore, the LLS scores above 131 were considered of high strategy users and LLS scores lower than 131 belonged to low strategy users. An F-test was used to determine whether the sample met the criterion of equality of variances. The F-observed $(\mathrm{F}=4.07)$ was more than $\mathrm{f}$-critical $(\mathrm{f}=1.51$, one-tailed). The sample did not meet the criterion of equality of variances. However, as Brown (1988) states, violation of the assumption of variance equality has little effect on the result of $t$-test if the sample sizes are equal (p.166). So, a t-test was done under the assumption of unequal variances. Having conducted the t-tests, the researchers discovered that high LLS use connotes having a high selfesteem level. That is, high LLS users reported a higher level of self-esteem than low LLS users $(\mathrm{t}-\mathrm{Stat} .=5.63$, $\mathrm{t}-\mathrm{Critical}$ one-tail=1.66, $\mathrm{df}=88$ ). The findings of the study revealed that the relationship between GSE and LLSs is positive and significant for the whole group. It was also found that gender is not a determining factor neither for GSE level (Fobserved $=1.08$, $\mathrm{f}$ Critical one-tail= 1.68$)$ nor LLSs preference $($ F-observed $=1$, $\mathrm{f}$ Critical one-tail $=1.68)$.

The same result was shown by a study conducted by Tahriri (2003), but it is in contrast with the finding of a study conducted by Cheng and Page (1989) and Pappamihiel (2001) that reported a higher level of self-esteem for males. Another result was that of Blackman and Funder (1996) who found that males and females experience a similar level of self-esteem. What Francis and James (1998) found was also in line with Cheng and Page (1989) with respect to selfesteem.

\section{CONCLUSIONS AND IMPLICATIONS}

Based on the statistical analyses of the obtained data, the following conclusions were drawn. There is a significant and positive correlation between the degree of Language Learning strategy Use and Global Self-esteem level. Of course, the causal relationship is not apparent in correctional analyses. However, strategy training and helping learners improve their self-esteem may have a mutual positive effect hence boost FL learning. Among the six strategy categories, 'cognitive strategies' have the most, and 'affective strategies' the least correlation with their corresponding 'selfesteem', respectively. An implication is that those students who rely on their mental processes to handle learning situations are those who attribute a greater degree of worthiness of themselves. The reverse could be also the case that if learners values themselves more it is more likely to resort to their mental capabilities for learning rather than using other 
strategies. This may be because both self-esteem and cognitive strategy type are personal compared to other types of strategies. Among all strategy items listed in SILL, item 33, i.e., 'I try to find out how to be a better learner of English' is the most frequent individual strategy; used by adult EFL learners. This is quite reasonable that every individual learner wants to perform well in his/her learning. Item 5, i.e., 'I use rhymes to remember new English words' is the least frequent strategy use by the same learners. The reason may be that using 'rhymes' is time-consuming and is not of interest for many learners. Besides, for most learning situations, 'rhymes' are nonexistent or a difficult to find. Finally, it was shown that gender does not play a role in neither 'strategy use' nor 'GSE level'. It is hoped that the findings of the present research help EFL practitioners to try to know their students better and decide accordingly.

\section{APPENDIX. THE RANK ORDER OF INDIVIDUAL ITEMS IN SILL}

\begin{tabular}{|l|l|l|l|}
\hline RANK & Q. No. & MEAN & SDDEV. \\
\hline 1 & 33 & 3.33 & 0.818637 \\
\hline 2 & 32 & 3.30 & 0.791942 \\
\hline 3 & 31 & 3.25 & 0.758158 \\
\hline 4 & 38 & 3.22 & 0.844341 \\
\hline 5 & 10 & 3.21 & 0.822597 \\
\hline 6 & 28 & 3.19 & 0.816879 \\
\hline 7 & 11 & 3.11 & 0.850902 \\
\hline 8 & 48 & 3.11 & 0.901747 \\
\hline 9 & 39 & 3.03 & 0.912015 \\
\hline 10 & 18 & 2.99 & 0.904101 \\
\hline 11 & 22 & 2.96 & 0.916662 \\
\hline 12 & 45 & 2.96 & 0.954534 \\
\hline 13 & 1 & 2.95 & 0.805322 \\
\hline 14 & 30 & 2.93 & 0.879647 \\
\hline 15 & 46 & 2.93 & 0.90631 \\
\hline 16 & 36 & 2.91 & 0.863948 \\
\hline 17 & 50 & 2.90 & 0.979416 \\
\hline 18 & 12 & 2.88 & 0.919181 \\
\hline 19 & 25 & 2.88 & 0.913863 \\
\hline 20 & 40 & 2.87 & 0.942743 \\
\hline 21 & 34 & 2.86 & 0.800419 \\
\hline 22 & 4 & 2.85 & 0.973656 \\
\hline 23 & 37 & 2.82 & 0.943604 \\
\hline 24 & 26 & 2.80 & 1.008215 \\
\hline 25 & 3 & 2.79 & 1.064123 \\
\hline & & & \\
\hline
\end{tabular}

\begin{tabular}{|l|l|l|l|}
\hline RANK & Q. No. & MEAN & SDDEV. \\
\hline 26 & 35 & 354 & 0.8695 \\
\hline 27 & 8 & 346 & 0.842117 \\
\hline 28 & 21 & 344 & 0.926765 \\
\hline 29 & 27 & 339 & 0.968185 \\
\hline 30 & 42 & 332 & 0.943207 \\
\hline 31 & 20 & 329 & 0.986853 \\
\hline 32 & 19 & 324 & 0.973528 \\
\hline 33 & 29 & 323 & 1.021638 \\
\hline 34 & 15 & 314 & 1.00654 \\
\hline 35 & 13 & 309 & 0.96437 \\
\hline 36 & 24 & 308 & 0.980117 \\
\hline 37 & 49 & 307 & 0.971343 \\
\hline 38 & 9 & 306 & 1.002808 \\
\hline 39 & 44 & 302 & 0.975324 \\
\hline 40 & 16 & 291 & 0.882909 \\
\hline 41 & 47 & 290 & 0.966894 \\
\hline 42 & 2 & 276 & 0.960278 \\
\hline 43 & 14 & 272 & 0.932009 \\
\hline 44 & 23 & 271 & 0.986916 \\
\hline 45 & 6 & 270 & 0.863659 \\
\hline 46 & 7 & 268 & 0.847296 \\
\hline 47 & 17 & 261 & 0.848033 \\
\hline 48 & 41 & 209 & 0.886652 \\
\hline 49 & 43 & 181 & 0.761366 \\
\hline 50 & 5 & 160 & 0.657226 \\
\hline & & & \\
\hline
\end{tabular}

\section{REFERENCES}

[1] Blackman, M. C., \& Funder, D. C. (1996). Self-esteem as viewed from the outside: A peer and gender perspective. Journal of Social Behavior and Personality, 11(1): 115-126.

[2] Blascovich, J., and Tomaka, J. (1991). Measures of self-esteem. In Robinson, J. P., Shaver, P. R., and Wrightsman, L. S., (eds.), Measures of Personality and Social Psychological Attitudes. Academic Press, San Diego, pp. 115-160.

[3] Brown, H. D. (2000). Principles of language learning and teaching (3rd ed.). Englewood Cliffs, NJ: Prentice Hall Regents.

[4] Brown, J., D. (1988).Understanding research in second language learning. New York, NY: Cambridge University Press.

[5] Burns, R., (1982). Self-concept development and education. Holt, Rinehart and Winston, London.

[6] Byrne, B. (2000). Relationships between anxiety, fear, self-esteem, and coping strategies in adolescence. Adolescence, 35.1, 201-215.

[7] Cheng, H., \& Page, R. C. (1989). The relationship among sex, academic performance, anxiety, and self-esteem of junior high school students in Taiwan. Journal of Multicultural Counseling and Development, 17(3): 123-133.

[8] Cohen, A. (1998). Strategies in Learning and Using a Second Language. London and New York, Longman.

[9] Demo, D. H. (1985). The measurement of self-esteem: Refining our methods. Journal of Personality and Social Psychology, 48, (p 1490-1500).

[10] Ehrman, M.E. \& Oxford, R.L. (1990). Adult language learning styles and strategies in an intensive training setting. Modern Language Journal, 74.3, 311-327.

[11] Francis, L. F., \& James, J. (1998). Is there gender bias in the short-form Coopersmith Self-esteem Inventory? Educational Research, 40.1, 83-88.

[12] Gurney, P. W. (1986). Self-esteem in the classroom. School Psychology International, 7, 100-209.

[13] O’Malley, J.M., Chamot, A.U., Stewner-Manzanares, G., Kupper, L. \& Russo, R. (1985). Learning strategies used by beginning and intermediate ESL students. Language Learning, 35, 21-46.

[14] O’Malley, J. M. \& Chamot, A. U. (1990). Learning strategies in second language acquisition. New York: Cambridge University Press. 
[15] Oxford, R. L. (1990). Language learning strategies: What every teacher should know. New York, NY: Newbury House Publishers.

[16] Oxford, R. \& Nykios, M. (1989). Variables affecting the choice of language learning strategies by university students. Modern Language Journal, 73.3, 291-300.

[17] Pappamihiel, N. E. (2001). Moving from the ESL classroom into the mainstream: An investigation of English language anxiety in Mexican girls. Bilingual Research Journal, 25.182, 31-38.

[18] Park, G. (1994). Language learning strategies: Why do adults need them? Unpublished manuscript, University of Texas at Austin.

[19] Riazi A., \& Almasian M. (2007). Creativity, language learning strategies and language proficiency. http://www.sid.ir/en/ViewPaper.asp (accessed 28/4/2013).

[20] Richards J. C. \& Schmidt R. (2002). Dictionary of language teaching and applied linguistics (3rd ed.). England: Pearson Education Company.

[21] Robin, J. (1975). 'What the "Good Language Learner" Can Teach Us'. TESOL Quarterly 9, 41-51.

[22] Rosenberg, M. (1965). Society and adolescent self-image. Princeton, NJ: Princeton University Press.

[23] Rosenberg, M., Schooler, C., \& Schoenbach, C. (1989). Self-esteem and adolescent problems: Modeling reciprocal effects. American Sociological Review, 54: 1004-1018.

[24] Rosenberg, M., Schooler, C., \& Schoenbach, C. (1989). Self-esteem and adolescent problems: Modeling reciprocal effects. American Sociological Review, 54, 1004-1018.

[25] Schumann, J., H. (1997). The neurobiology of affect in language. Cambridge, MA: Blackwell.

[26] Schumann, J., H. (1998). The neurobiology of affect in language. Language Learning 48, Supplement 1, Special Issue.

[27] Stern, H., H. (1975). What can we learn from the good language learner? Canadian Modern Language Review, $34,304-318$.

[28] Tahriri A. (2003). EFL learners' foreign language classroom anxiety and its relationship to their global self-esteem. MA thesis, Shiraz University, Shiraz, Iran.

[29] Watanabe, Y. (1990). External variables affecting language learning strategies of Japanese EFL learners: Effects of entrance examination, years spent at college/university, and staying overseas. M.A thesis, Lancaster University, Lancaster, U.K.

Amir Asadifard is currently a PhD candidate in Teaching English as a Foreign Language in Khorasgan Azad University, Isfahan, Iran. His areas of interest include Discourse analysis, Testing, and CALL.

Reza Biria currently works as an Assistant Professor at Khorasgan Azad University, Isfahan. His research interests include teaching English as a second and foreign language and ESP. 